University of Nebraska - Lincoln

DigitalCommons@University of Nebraska - Lincoln

September 1987

\title{
Evolution of Time Constructs and Their Impact on Socioeconomic Planning
}

F. Gregory Hayden

University of Nebraska-Lincoln, ghayden1@unl.edu

Follow this and additional works at: https://digitalcommons.unl.edu/econfacpub

Part of the Economics Commons

Hayden, F. Gregory, "Evolution of Time Constructs and Their Impact on Socioeconomic Planning" (1987). Economics Department Faculty Publications. 8.

https://digitalcommons.unl.edu/econfacpub/8

This Article is brought to you for free and open access by the Economics Department at DigitalCommons@University of Nebraska - Lincoln. It has been accepted for inclusion in Economics Department Faculty Publications by an authorized administrator of DigitalCommons@University of Nebraska - Lincoln. 


\title{
Evolution of Time Constructs and Their Impact on Socioeconomic Planning
}

\author{
F. Gregory Hayden
}

The primary focus of the institutionalist perspective is instrumentalist problem solving. Problems are delivered by the institutional process and solved by altering the social structure. To solve socioeconomic problems, planning is necessary. Important to any planning is the question of when actions and events are to occur. To effect new social structures, actions and events must be properly sequenced. An analytical core of sequencing events is time analysis. John $\mathbf{R}$. Commons stated that, in addition to knowing what to do, the economist who has the power and responsibility for planning "must know what, when, how much and how far to do it at a particular time and place in the flow of events. This we designate the principle of timeliness." 1 This is not consistent with the common approach to time analysis. The more common approach leaves us at the mercy of passing time.

An experiment worth performing is to ask a group of university sophomores to take out a piece of paper and write a brief answer to the following question: What is time? In the years I have performed this experiment, only once has a student referred to what had been learned in a physics course. Again and again the students express the common bias of Western feelings regarding time. "Time is eternally passing." "Time is flowing past almost unnoticed." As one sophomore so vividly

The author wishes to express his appreciation to the Social Science Journal and to the Journal of Economic Issues for permission to reprint parts of past articles in this article. 
explained, "the second that is here now will soon be going over the mountains and travel on to California." Most of us are not so graphic in our explanation about passing time but most of us believe the common misconception that time is a flowing reality that is constantly passing. The common view is wrong. We have not seen time flowing by, no one has measured it flowing by, heard it, or even recorded any telltale signs of its passing, yet the Western mind continues to hold to the common view. The flowing stream of time is so vividly believed that people seriously consider that the loss of aircraft over the Bermuda Triangle could be because of warps in the time stream, and neoclassical economists seriously recommend that education should be delivered to children on the basis of the outcome of a discounted time stream.

Time is not a natural phenomenon; rather it is a societal construct. What exists in society are duration clocks and coordination clocks selected by society, and the sequencing of events as scheduled by societal patterns.

In modern paradigms, time does not flow, or go, or run from here to there in either a cyclical or linear pattern. It also does not bridge a spatial gap between points. Time is a relative concept that relates one motion to the duration of another motion-a clock. In traditional concepts, motion and succession were thought to take place in time. Today motion defines time. The duration between successive events is measured by still another motion, such as atomic vibrations or hour clocks or color changes. The successive events are not connected by any rope of time or temporal plane. With so many items in motion, the universe is full of clock candidates. Since these items are moving in a multitude of directions, we might want to say that time is multidirectional. But that would be inaccurate. Time is the duration of motion. It has no direction.

There is no future into which the world is destined to flow except in the sense of the "after" that follows the "before." This certainly removes a good bit of the glow of destiny, inevitability, and evolutionary progress contained in the old concepts of time and future. Or, stated differently, the modern concept of time allows us to use clocks to regulate events rather than ourselves being regulated by the running clock of passing time. This expands the discretionary role and responsibility of modern planners.

\section{Social-Cultural Time Constructs}

To find social time it is necessary to observe the cultural symbols 
and institutions through which human experience is construed. Our own Indo-European language imposes the concept of time on us at a very early age, so it is difficult to identify with the concept of timelessness. Societies do exist without a consciousness of time, but most societies possess some concept of time. Conceptualizations of time are as varied as the cultures, but most can be categorized by one of three images. Time in the broad sense is viewed as a line (linear), a wheel (cyclical), or as a pendulum (alternating phenomenon). But within these central images, numerous other distinctions are made. One is tense. Is there a past or present or future, or all three? If more than one, to which is the society orientated and in what way? Another is continuity. Is time continuous or discontinuous? Does the continuity or hiatus have regularity? Another is progressiveness. Is evolutionary transformation expected with the passage of time? Still another is use. Is time used for measuring duration or for punctuality? In addition, the metaphysical distinctions are numerous. Is there a mode for measuring time? Is it reversible or irreversible? Subjective or objective, or both? Unidirectional? Rectilinear?

\section{Various Cultural Times}

These distinctions come into focus when one studies various cultures. The Pawnee Indians, for example, have no past in a temporal sense; they instead have a timeless storehouse of tradition, not a historical record. To them, life has a rhythm but not a progression. ${ }^{2}$ To the Hopi, time is a dynamic process without past, present, or future. Instead, time is divided vertically between subjective and objective time. Although Indo-European languages are laden with tensed verbs and temporal adjectives indicating past, present, and future, the Hopi have no such verbs, adjectives, or any other similar linguistic device. ${ }^{3}$ The Trobriander is forever in the present. ${ }^{4}$ For the Trobriander and the Tiv, time is not continuous throughout the day. Advanced methods of calculating sun positions exist for morning and evening, but time does not exist for the remainder of the day. ${ }^{5}$ For the Balinese, time is conceived in a punctual, rather than a durational, sense. The Balinese calendar is marked off, not by even duration intervals, but rather by self-sufficient periods that indicate coincidence with a period of life. Their descriptive calendar indicates the kind of time, rather than what time it is. ${ }^{6}$ The Maya had one of the most complicated systems of time yet discovered. Their time divisions were regarded as burdens carried by relays of divine carriers-some benevolent, some malevolent. They would succeed each other, and it was very important to determine who 
was currently carrying in order to know whether it was a good time or a bad time. (Was this an early explanation of business cycles?) The most common explanations of time among human societies, however, are the cyclical ones.

\section{Cyclical Time}

Two examples of cyclical time are those of the ancient Greek and Indian. Socrates believed his teaching was not new-he had repeated it in cycle after cycle for many lives. Aristotle denied the logical possibility of movement in a straight line to infinity and believed that the only everlasting continuous motion is circular motion. An example of cyclical time still in existence is found in India.

As in most Indian thought, spirituality plays a major role. For the Western mind to absorb the meaning of Indian time requires more than the average mental and emotional stability in order to survive. To begin with, one is dealing with more than one cycle, with more than one God, with numerous qualities and quantities of time, and with astronomical figures. For example, one day and one night for Brahma, in which a universe arrives and is destroyed, is equal to 4,320,000,000 human years, and this pattern will exist for 100 years of Brahma. But this is only the beginning; there are time cycles within the great cycle, with the Mahayuga consisting of four ages, each of which is longer than our historical records. One thousand Mahaygas make up a Kalpa and fourteen Kalpas make up a Manvantra, and on and on and on. ${ }^{8}$ For the present purpose it is enough to note that man and history become quite insignificant in comparison to time. This has a tremendous impact on social and economic life. At birth, each person receives a dhrama-a moral code and duty appropriate to a given status and pattern of life.

The joint belief in station and association obligation (dharma) and in the related cycle of existence (karma) serves as cement in uniting the caste system, and jajmani economic system, and all superior/inferior relations....

The idea of karma is additionally associated with a cyclical view of human and natural history. Annual crop and seasonal changes are circularly recurrent. ... A man's life also is a cycle, and karma emphasizes the rhythm of life and death and rebirth. Because the world is viewed in terms of recurring cycles, the notion that a society might advance systematically in any way (i.e., the concept of "progress") does not naturally present itself. ${ }^{9}$

Clearly time concepts in India affect the economy there as do the time concepts in any society. 


\section{Western Time: Traditional}

As stated above, Western temporal constructs are consistent with the idea of the linear flowing stream. "But in the broad sweep of human existence, that way of constructing the dimension of time is relatively rare." 10 The traditional Western linear time-stream came into being with Christianity; however, seeds of it had been alive for some time. For example, in the third century B.C., Strato said, "day and night, a month and a year are not time or parts of time, but they are light and darkness and the revolution of the moon and sun. Time, however, is a quality in which all these are contained."11 This quote illustrates the appearance of flowing time to explain succession. Through the experience of succession, the appearance of time as a separate eternal entity suggests itself. The reality exists only in the appearance.

What was left of cyclical time among the Romans died with Christ. Christ was not a mythical entity. He was on earth and a part of history. Since he died as a man and for all, he could not die again as in cyclical time. Time must be linear. His death "was a unique event. It had happened, once, here on earth, in a certain place at a certain time, and any suggestion that it could happen again was a whisper from the devil." 12

Augustine rejected Aristotle's connection of time and motion, and avoided any confusion of temporal with spatial concepts. He argued that time was found in the soul and in the mind. Christ died for our sins and man now moved forward into a sacred prophecy-fulfilling future. ${ }^{13}$ History would flow from one prophesied interval to the next until the final judgment. Christianity became an onward religion. "The time series is linear ... in the sense that it had a definite beginning at the creation of the world; it will have a definite end when Christ returns at the Last Day; and between these two limits it manifests, at least in a general way, the working out of a consistent Divine Plan.... The movement towards its fulfillment does give a direction and purpose to the time series." 14 Time gave Christians opportunity. "The certitude that time is useful and opportune clearly belongs to the conscious tradition of Christians; for them time is not an inert thing nor is its course a simple chronological unfolding without aim."15

The place of the individual Christian was, first, to order his whole life down to the last detail with a view of growing in the love of God, and second, he must ever be alert to accept God's grace. ${ }^{16}$ Thus the idea of the atomistic individual concerned with growth and progress along the inevitable stream of time becomes apparent. In order to build God's community for His glorification on earth and the saving of souls, a positive work ethic was necessary. One was to be judged not only for 
good works but for good work as well. A Benedictine monastery's appreciation of labor is revealing: "Labor was to be man's greatest joy and the instrument of his union with God. Industry was the key to the upbuilding of the new world that Benedict created. ... Everything was seen as an aspect of work." 17

Since so much building, caring, and praying needed to be done, with no idea how much time was left, time became precious to the medieval mind. Both the individual and the Kingdom could be called before all the preparation was completed. "Thus, early Christian ideology also created a fertile ground for technological innovation and its employment for earthly improvements." 18 The more that could be done with passing time, the better. Since individual and community were committed to sacred and earthly accomplishments, accountability and measurement became important. The Christian Middle Ages achieved "an ordered society, sustained by a common and not ignoble belief, in which the individual was not lost but discovered himself, not suppressing but releasing joyous energies, reaching to the sky in the shape of cathedral towers, for the glory of God."19

Although the object of the glory has changed considerably, Christian time remains. It is a passing time without qualitative changes, to be used efficiently. At one time the object of the efficiency may be commercial interests, at another technology, at another Mammon, but the concept of time has not much changed.

The enlightment really did not alter traditional time concepts. Newton's time was Christian time, and despite Leibniz's argument that time is relative and that instants apart from things are nothing, the traditional concept of time was predominant in the scientific community until much later. Not until Einstein dealt with time on micro and macro levels did the scientific community change. However, the traditional view remains predominant today as the "common sense" view of time, and as the neoclassical view. Neoclassical assumptions regarding time are a continuation of its religious predecessor.

In neoclassical thought, individual consumption replaces religious glorification; thus the present becomes more important and pressure exists for individuals to get their fill before their time runs out. This is part of the transition from "biblical time" to "merchant time."

\section{Neoclassical Time-Stream Discounting}

Neoclassical thought puts its temporal construct into operation through the use of the geometric mean discounting formula. Consistent 
with its tradition, neoclassicalism borrowed the discounting tool from the world of capitalist finance. It was appropriate for the financier's portfolio analysis, but it is not appropriate as an evaluative tool for social policy. A review of the basic premises and assumptions involved in using the discounting technique makes it clear that they are not consistent with modern science. They are:

Isolation. Time analysis should be built around an isolated extrapolation or projection of segregated benefit and cost flows as opposed to an analysis of process integration. This stems from the analysis being atomistic and isomorphic, instead of holistic.

Importance. Time discounting should occupy a position of major importance in social evaluation. If resources constrain an analysis, then the research and organization of data for discounting should be the last to be eliminated. Thus, enormous research effort has gone into determining the correct discount rate for water projects, with very little research focusing on matters such as the effect of water projects on the quality of community life.

Measurability. What is important is measurable. Matters that are represented by numbers are the most important.

Consumer Desire. Evaluation of merits and flaws, benefits and costs, should be consistent with a philosophy that promotes consumer desire, even in those cases where there is no vehicle for registering such consumer desire.

Valuing Benefits and Costs. Both benefits and costs can be valued by the same common denominator. Pecuniary prices can serve as this common denominator, which takes account of relative scarcities and surpluses.

Closed Future. The future is closed, which assumes that there is a future out there, instead of assuming that there are numerous potential futures.

Big is Beautiful. More is better than less. The passage of time requires progress. The greater the present worth, the more superior a project is judged to be. The present worth is increased by increasing net benefits.

Existence of Time Preference. Neoclassicalists assume, tautologically, that since interest rates accompany saving and consumption by individuals, it follows that individuals have independent time preferences.

Time-Preference Judgment. Individuals have an inherent, intuitive, internal ability to judge time, both durational and continuous. Individuals have independent time preferences and can make judgments regarding them. 
The Present is Most Important. The present gets top priority. Even though the additional hospital beds, for example, will not be needed for five years, they should be discounted through time and assigned a value for the present period when they are not needed.

Linear Proportionality. In addition, the correct fit for the time preference function is the linear proportionality of the geometric mean formula. Thus, time-stream discounting also assumes that social time preferences are expressed best through percentage rates.

The Commonality of Clocktime. The same time-measurement scale (clock) has the same meaning in different systems and across different institutions or can be used as a common denominator of different systems. This assumption means it is not necessary to develop a clock consistent with the system.

A Common Discount Rate. The same discount rate is correct for costs as well as benefits, and is correct for all kinds of costs and benefits.

The Existence of Time. Time exists as part of the physical world. Therefore, discounting can take place over time and through time, and events can take place in time. Humans, as well, are in time.

Commodity Value. Because time exists, it can be scarce. Because it is scarce, it can and should be valued as a commodity.

Rectilinearity and Forward Flowing. Time in neoclassical theory is what usually is identified as the Christian or Indo-European conceptualization of time. It is one-directional, moving into the future in a linear fashion. Time was switched on in the beginning and is still running.

Unidimensional and Absolute Character. Time is one-dimensional in its nature, texture, rate, structure, setting, and the like. These characteristics remain absolute in the neoclassical analysis.

Flowing Stream. Time is a flowing stream; thus the nomenclature "time stream analysis." Like so much of the rest of neoclassical theory, time, as a stream, comes from Newton. In the beginning of the Principia he said, "Absolute, true and mathematical time, of itself, and from its own nature, flows equally without relation to anything external." Although this statement is consistent with traditional Christian thought starting at least as early as Augustine, once Newton articulated it, it reified time and ascribed to it the function of flowing. Although from the beginning this reification was challenged and denied by others of equal fame such as Leibniz, Kant, Einstein, and Planck, they never were able to remove it from the public mind because of the general cultural and religious reinforcement. Later generations of physicists, astronomers, and philosophers were able to erase traces of Newtonian 
time from their models, but it is still basic to neoclassical time analysis.

Continuously Passing Time. Not only is it a stream, but the stream is continuously passing-running on and on and on. Flowing. Flowing. As the moralist cautions, "Make the most of time. Use it before it goes."

Infinite. Time is an infinite open set. The stream without definable banks is also without final destination.

Time Hypostatization. Many of the above assumptions are a result of what logicians refer to as time hypostatization. To hypostatize time is reification along with the creation of qualities and attributes. The neoclassicalist reification of time is a confusion between time and the experience of succession or sequence.

Time Spatialization. In conjunction with hypostatization, it is also necessary to practice time spatialization in order to see the neoclassical time-streams flowing ever outward. To spatialize time is to attribute spatial qualities to time or to confuse the spatial relations among things with the temporal relations among events.

Integrated Definitions. As in Christian time, duration, continuity, and sequence are integrated into one common definition. Time, usually designated by $T$, is an endless rectilinear stream made up of moments. An event takes place in a moment in $T$ and a sequence of events is spread over the stream of moments. The interval between moments is duration, usually designated by $t$, thereby defining $t$ as a piece of $T$. In this definition, reversibility and irreversibility are ignored.

Space-time Continuum. Separation of time and space. Although all sciences-from physics to anthropology-recognize the impossibility of separating time and space, the neoclassical discounting formula does not provide for a means to integrate the spatial aspects of the spacetime continuum.

\section{Western Time: Modern}

To understand the modern concept of time, let us begin by conducting an imaginary experiment. Let us for a moment imagine that our sensing faculties are suspended in a universe of nothingness. Now look out into the empty space. There is no time. Now suspend one stationary item in the nothingness. There is still no temporal dimension. "If we try to imagine ourselves in a world without sound or movement, with nothing stirring, without even our breathing or heart-beats, we must agree that we cannot have Time there. Time may not be merely something happening, but unless something is happening, there cannot be 
Time." ${ }^{20}$ Now let us allow our suspended item to make one move and stop. What was the length of the move? We can see the length of the distance, but there is no measure for the temporal duration because there is no other motion to use as a time clock. If a second item is added to this universe, its rate of movement can be used as a measure of the duration of the first item's movement. We now have a relative time clock. We see that time is relative and duration is relative to another motion. Now let us fill the universe with items moving in a multitude of directions, in a multitude of spatial patterns, and at a multitude of rates. Now the universe is full of potential clocks and full of time dimensions. Since these items are moving in a multitude of directions, we might want to say time is multidirectional. However, as stated in the introduction, that would be incorrect. Time is the duration of the motion. It has no direction. The multitude of moving items is not flowing into the future. The earth is rotating around the sun, the bus is traveling about the city, and the barking dog is running about the yard. With this in mind, philosophers sometimes refer to reality as an infinity of layers of now. But to this author the words "infinity," "layers," and "now" suggest the old ideology. Reality cannot be broken into layers. Layers implies up and down, thus implying direction to time, and we are right back into the original problem of hypostatization and spatialization. In truth, the earth, the dog, and the sun are processing in the here and now. They are not flowing anywhere and neither is time.

Time becomes the duration between the "after" that follows the "before." For example, one of the dog's feet hits the earth after the other, or one tool development follows the other, and these durations can be measured with some other motion. This certainly takes some of the glamour out of the old concept of future, but more importantly, it also removes the idea of the inevitability of the future and removes some of the urgency of constantly being concerned that our lives are coming to a close. The old concept informs us that time is passing, and if we do not hurry, time will be wasted and the future will pass us. As stated above, the modern concept of time allows us to use clocks to regulate events rather than ourselves being regulated by the running clock of passing time. Humans can slow growth without feeling guilty of cheating posterity. This places men and women squarely in the decisionmaking roles of deciding when events should take place. In the old view of time, the relation of "earlier than" and "later than" was absolute and permanent because if an event is ever earlier than another event by a definable interval, it is always earlier, and by that interval. Yet we know that the sequence of events can be changed, reversed, slowed, accel- 
erated, or destroyed. Modern time concepts do not provide for inevitable patterns.

One of E.F. Schumacher's shortcomings, this author believes, was his failure to identify the importance of the temporal construct held in the consciousness of the people he was asking to alter their commitment to growth. Because he did not identify the main determinate of the constant push for activity and accomplishment, he could not recommend a viable solution or policy. He could not tell us why we felt compelled to do what we were doing.

\section{Time Analysis Should be Consistent With Holistic System}

In modern thought, time is no longer an exogeneous concept but rather another element in the sociotechnical system. When we are planning for a complex sociotechnical system that is constantly evolving, we should not seek a single mechanistic synthesizer of temporal concerns.

\section{Different Clocks for Different Institutional Processes}

In order for a social plan to sequence and coordinate social delivery successfully with concomitant "linking-points," planners should be aware that different temporal conditions occur for different kinds of institutional experience. There can be a difference in temporal rhythm and temporal clock from institution to institution. Not only does time change from society to society, it changes among institutions, especially in a complex society. "Time scales may differ greatly over the hierarchical levels of a large system."21 One time and one clock do not exist across institutions as is assumed in neoclassical thought. One institution may require an even temporal rhythm in the movement of resources, people, and goods. Another may require a relentless pace. Still another may go in impatient jerks, alternating between tremendous bursts of intense activity and long durations of plodding activities.

A simple example of different clocks in our society is the example of baseball and the effect of baseball games on transportation delivery systems. Baseball pays no heed to the hour clock, or to Einstein's atomic vibrations for that matter. Baseball has its own special time. It depends on outs, not minutes. Six outs to an inning, rather than sixty minutes to the hour. The duration of a game is determined by the correct number of innings, which may be two to five hours in non-baseball time. This difference in clocks complicates the delivery of transportation and 
police for taking the fans home while meeting the needs of those on alternative clocks. If the existence of alternative clocks and time are ignored, as in neoclassical analysis, problems are created.

Temporal variation in Brazil is related by Manfred Max-Neef. For example, he explained the frustration he had experienced in a Brazilian town. He was the only person in town who regularly lived by the dictates of a watch while the time of others was regulated by events. "In the short term, by daily events: things are done before or after mass, before or after school classes, after the Town Hall meeting, and so on. The long term is planned and regulated in tune with the religious and patriotic feasts of which there are, of course, a lot. A person's involvement with the preparation of a feast is a duty that takes precedence over any other type of commitment." ${ }^{22}$ Max-Neef has found that the lack of concern for different temporal constructs in Third World countries can lead to a serious "human state of temporal asynchrony. These asynchronies produce varying degrees of anguish and anxiety, according to the importance given by the person concerned to the bonds of frustrated communication." 23

However, Max-Neef pointed out that different times need not lead to frustration. To avoid the frustration, it is necessary to be sensitive to, and to integrate the different space-time dimensions in the social system. Social time integration is emphasized in the final section of this article. However, for now let us review the integration of alternative space-time that Max-Neef found in the town of Tiradentes, Brazil. He said:

Time was there, of course, and so was space; but there was something different as well. I had the strong sensation that I was living a "contemporaneousness of the not-contemporary." The mules and the cars, the Chafariz and the television, the sun-dial and my Casio lithium watch. All widely diverging eras co-existing in the midst of a space of incredibly generous perspective. I remembered having been in many old cities before, and my sensation was almost always "time asynchronic": i.e. modern life going on at its usual rapid pace in museum-like surroundings. Here it was different. Times seemed to be synchronized because of the basically tranquil pace and style of the people's forms of human interaction. People were not in a space; they integrated into their space. They defined their own space and made up their own time, thus generating a splendid spacetime coherence. It suddenly occurred to me that it was probably very difficult to develop gastric ulcers in a place of this kind. Sometime later I was to discover several forms of space-time disruption, yet this initial impression remained the overriding one for as long as I lived in Tiradentes. ${ }^{24}$ 


\section{Individual Subjective Time Is Not Acceptable}

For economic and social decisionmaking, one of the most dangerous analytical techniques available in dealing with time is the old philosophical technique of turning to individual intuition. "[Henri-Louis] Bergson, an original and bold if rather reckless philosopher, based a whole philosophy on the idea that outer or chronological time is unreal and that reality can be found only in our inner sense of ... psychological time, the unceasing and creative flow of which we have an immediate apprehension." 25 Nicholas Georgescu-Roegen made this same basic mistake. He said, "there is no other basis for Time than 'the primitive stream of consciousness'."26 The problem with this approach is that the analyst is right back where he started; for intuition is only the well filled with our sociocultural groundwater. As Einstein and Infel said,

The method of reasoning dictated by intuition was wrong and led to false ideas of motion which were held for centuries. Aristotle's great authority throughout Europe was perhaps the chief reason for the long belief in this intuitive idea....

The discovery and use of scientific reasoning by Galileo was one of the most important achievements in the history of human thought.... This discovery taught us that intuitive conclusions based on immediate observation are not always to be trusted. ${ }^{27}$

The first ability one must acquire is to look outward-not intuitivelyfor the human being has no internal time or internal time clock. Time clocks are social and time concepts are cultural.

Robert E. Ornstein pointed out how early psychologists made the mistake of looking inward for a biological clock (similar to William Stanley Jevons's search for an internal utility calculator). He stated:

Many psychologists, ignoring that ordinary temporal experience is personally and relativistically constructed, have searched for an internal organ of duration rooted in one biological process or another. This postulated "organ" has been termed a biological clock. Again, this search follows from the "sensory-process" paradigm of how we experience time, used primarily by those who would try to determine the "accuracy" of our time experience in relation to the ordinary clock. Such thinking confuses, once again, a convenient construction with reality. ${ }^{28}$

Social psychologists find that each year people in the United States have a poorer perception of the rate at which events are happening. 
That is, they underestimate by a greater amount each year the interval of calendar time between when they expect events to happen and when they actually happen. This psychological phenomenon was an integral part of Toffler's book, Future Shock, in which he explained that futures are coming at us too rapidly for people to prepare for them psychologically. But for the present purpose, this phenomenon certainly should make suspect any attempt to base social planning in a technological society on a personal conception of time or time preferences.

French speleologist Michel Siffre found that after staying in a subterranean cave, which was dark and far out of sight and sound of his fellow humans, without any means of recognizing succession or discovering how clock time was passing, the length of the underground stay was completely misjudged. In Siffre's case, "He found to his astonishment that he had been far longer in his cave than he had imagined. We must note first that no intuitive sense of time had worked for him; that little watchman from the unconscious had gone off duty.... Then, his psychological time had lost touch with clock and calendar time." 29

The reach for psychological time tends to sidetrack any real attempt to solve the problem of social time. First, social life cannot be coordinated with psychological time. The railroad uses clock time for its train schedules-not psychological time. Second, as Priestly pointed out, psychological time crams into one category too many quite different sorts of experiences. ${ }^{30}$

An additional problem with attempting to develop a succession concept that depends on individual time is that individual time changes with the individual's basal brainwave rate. "All that we experience as external reality is apparently nothing more than patterns of neuronal energy firing off inside our head." ${ }^{31}$ Time, therefore, is not even a constant-even given a constant social situation-within an individual brain. In "ordinary" waking moments the brainwave rhythm, beta, is firing at approximately twenty-four frames per second (to use a movie projector concept). However, if slowed to a firing rate of ten waves per second, or alpha rate, the second hand on the clock appears to have slowed to approximately half its former speed. If the blasts are slowed to theta, or five blasts per second, time seems to stand still. "When brainwaves are still, time stands still, and when time stands still the illusion of motion becomes impossible ... to the individual." 32 Time and motion correspond to the individual's current brainwave rhythm. In various states of consciousness, time and motion may be slowed, increased, intermitted, or run backward. By reducing the rate of spheroid blasts, as in meditation, one can fall through the gaps between 
the firings, and, to use current jargon, become "spaced out." Thus, if we are to follow Georgescu-Roegen's suggestion to use stream-ofconsciousness, we will first have to know whether it is at the alpha, beta, theta, or delta rate.

Psychological predilections for time preference can be allowed to run free and wild, and even lead and lag, but if social clocks are not coordinated by an objective social time outside and above the individual psyche, then a slight miscalculation of timing, for example, can place one jumbo jet in the path of another. Individual preference, basal rate, or intuition about time or the speed of the plane are not important. To deliver air transportation safely, pilots and controllers must be coordinated on a common system.

\section{Timeliness Requires Planning Decisions Be Above} the Atomistic Level at the Holistic Level

In determining the most timely delivery of social programs, it is necessary to take a holistic and organic view of institutions. Depending on individual perceptions, attitudes, and preferences with regard to time and time allocation is very misleading. Individual survey results have no correlation with what institutions actually require. F. Stuart Chapin, Jr., discussing Stuart Cullen's work on this issue, has said, "since much of the average weekday is tied up in routines over which people have little day-to-day control, the sequence of a day's activities in the life of an individual is 'pegged' around key structuring episodes. ... Stuart Cullen sees both practicalities and conceptual problems standing in the way of applying utility-maximizing concepts or in explaining behavior in terms of preference analysis." ${ }^{33}$ Chapin expanded on this issue saying, "rarely do preference studies present choice alternatives in the framework of constraints under which choices must be made. In study after study where preferences are followed up in an investigation of actual behavior, the correspondence between behavior has been of relatively low order." 34 This result would not surprise holistic social scientists. For that reason Chapin recommends the holistic approach for sequencing urban public programs. He said, "the view taken here runs counter to the reductionism bias in much of present-day scientific inquiry. But this view is not so much in reaction to these biases as it is a bias in the opposite direction, a strong belief in the necessity of a combinatorial emphasis of 'whole cloth' view which defines the contingencies of human activity in terms policy makers can recognize, evaluate, and project." 35 
In addition, the individual varies according to numerous matters such as race, class, recent employment, income, past achievements, and all those matters that color attitudes, estimates, and preferences. However, regardless of class, race, or employment record, the trains have to run on schedule.

\section{From Time Discounting to Timeliness In a Holistic Frame}

For society to function, it must be an integrated process-integrated into an organized effort by social forces. Before a construct can be designed to assist in temporal evaluation and decisionmaking, it must be understood, as Karl Polanyi emphasized, that society is an integrated system. Planning is the process of instituting new projects into the integrated system so that the right amount of social goods and services are delivered at the right point in the social system. This calls for Polanyi's concept of sufficiency: earmarking a sufficient amount to fill the needs of the system.

Time, if it is to be integrated usefully into social planning, should be what usually is connoted by the word "timely." Timeliness requires that we ask the question: Which projects will deliver the right amount of social goods and services at the right point in the social process to allow for the integration, maintenance, and improvement of the social fabric? It is not a matter of the neoclassical "firstest-with-the-mostest" criterion, but rather planning for the coincidence or congruence of the delivery system with need. For example, let us assume that we are able to discern that social forces are such that the future includes a great increase in lung disease in ten years. Timeliness requires that our plan provide for the delivery of the needed care in ten years. That care is not of value today when it is not needed. When planning is done on a substantive basis, rather than a pecuniary one, it becomes apparent that a pneumonectomy cannot be provided today and reinvested for a greater output of pneumonectomies later when needed. The sociotechnical system itself must define the temporal entities such as time clocks and temporal sequencing of events. How much, when, and how fast are questions that should be answered by system needs instead of a maximization principle. Therefore, "timeliness" best connotes the temporal concept that should guide project evaluation. If railyards or school buildings are needed at one point in the system evolution, that is when they should be delivered, not at an earlier point in order to increase the dividend found by a geometric mean discounting technique. 


\section{Project Evaluation for System Integration}

For planning purposes, evaluation should assist in making decisions about the coordination of collective social motions and activities, and about the sequencing of events. When the social sequencing approach is emphasized, time is no longer thought of in relation to continuity, but rather in relation to duration between sequential events. A time clock is not measuring a continuous stream of moments, but rather is a motion that has been chosen as the instrument for measuring the duration of other motions, or duration between events.

To accomplish such temporal evaluation, three concerns must be implemented into the evaluation. First, Walter C. Neale's definition of the function of an institution becomes very important to integrated systems planning. ${ }^{36}$ For Neale, the function of an institution concerns the interaction of one institution with another, and the mutual reinforcement of the institutions. Thus the function of alternative policies and programs must be judged to be in accordance with the needs of other system components. The new process should be structured to fit in another process, both along and across sequences. How much is needed depends on what is to be provided to other institutions. More is not always better.

Second, and closely related, is the knowledge acquired from anthropology regarding flow levels. "The flows of goods, services, information, and people through the network both structure and maintain ... community relationships." 37 Formal models emphasize rates, but institutionalist ones emphasize the integration of levels. ${ }^{38}$ For example, the flow of real outputs will exist only if there is an adequate flow of productive inputs, and the output will be sold if there is an adequate flow of buying power. "Only the values of levels are needed to describe fully the condition of the systems," because societies organize around levels. "Rates do not control other rates without an intervening level; no rate variable depends directly on any other rate variable. A rate equation is a pure algebraic expression." 40

Third, consistent with and necessary for integrated systems and temporal fit, is the structuring of a system without surpluses. ${ }^{41}$ An excess either of food or pollution is wasteful. Waste is misallocated surplus that does not fit the system; pollution ceases if the system is structured properly. For example, urban sludge can be turned into a valuable resource if the system is redesigned to recycle it back into agriculture in a timely manner. If a system is structured properly, surpluses do not exist. 


\section{Real Time Control Systems}

Temporal evaluation that judges whether a project correctly sequences the delivery of impacts with system needs is consistent with the basic concepts of computer science real time. Real time systems relate to the sequential events in a system, rather than to clock time. ${ }^{42}$ The system itself defines when events should happen. Real time systems have been used mainly to monitor and control systems by minimizing response time to system deviations. For example, if the monitoring device in a multi-color sheet-fed press (which uses advanced real time systems) detects a color deviation from the established standard, the control system brings the color back to conformance. Or, as another example, the chemical effusion that prepares plants for winter dormancy and enables them to germinate when the last frost has passed is a real time system. A failure of this real time system would cause a plant's extinction. Plants have of necessity evolved appropriate timing mechanisms to insure their survival. As the length of the day changes, leaves take account of it through the blue pigment phytochrome. Through the interaction of phytochrome and the internal daily rhythms of the plant, there is a change in the production of the inhibitory growth chemical abscisic acid, which plays an important role in the regulatory physiology of the plant. The plant would be in trouble if it attempted to maximize the net present value of abscisic acid instead of coordinating and controlling in a real time sense with ecological needs. As Harold Sackman has stated, "control is the process of assuring the conformity of plans and events. Real time control requires that the response of each element of the control system is such that the combined effect of all elements produces results that are sufficiently expeditious to preclude failure of the system." 43 Sackman emphasized that real time control is structured around events in an operating system, and does not try to force events to fit into temporally invariant molds. ${ }^{44}$ The continual monitoring of real time control systems "reaches its epitome with computer-based systems, where the computer can act as a built-in laboratory to collect information automatically on how well the system is performing, whether it is achieving its goals or not. But this has to start originally with a plan."45

Sackman saw real time as a step toward fulfilling John Dewey's philosophy. He said, "the twentieth century is witnessing the development of a new and practical attitude toward time, an attitude of designing and constructing the fixture through planning and control. Dewey sensed the demise of spectator attitudes toward time and anticipated the trend toward working control." 46 
Sackman also predicted that a concern for real time control would guide the evolution of other real time developments. ${ }^{47}$ That is the purpose in this section: to develop real time evaluations that must precede project selection and real time control. Of course, real time control will still be necessary after system implementation.

\section{Real Time Evaluation}

In order to synthesize the concerns of Polanyi and Sackman into a real time evaluation, let us begin by looking at a simplified Matrix and Environmental Residuals for Energy Systems (MERES) flow chart (represented in Figure 1) of corn cob gasification and electric generation, and use it as an illustrative vehicle. ${ }^{48}$ Figure 1 depicts the extraction of corn ears and the processing of electricity from the cob. The sequence of activities is identified across the top of the figure and a trajectory of processes to accomplish these activities is identified by the horizontal lines. Depending on the circumstances, different processes may be required to accomplish the same activities. For example, different methods may be used in the same plan to store the cobs.

The system is maintained by a sufficient flow through a production process, not by the flow of a time stream. The flow in the process changes with the production mode. Unlike the assumption about the one-dimensional undifferentiated time stream, the material flow through the instituted processes is differentiated and quite defined. The flow does not, as Newton said about time, flow from its own nature. Neither does it, to call on Newton again, flow "without relation to anything external." It flows according to the instituted process sequence of the activities across the top of Figure 1. The sequence is not designed around a linear time path. Some of these processes, such as gasification and generation, take place continuously throughout the Gregorian calendar. Sequences are designed by investigators; corn cob gasification is designed around a sequence of activities that change the form of energy from stored photosynthesized energy to electrical energy.

Real time evaluation requires system compatibility. Assume, for illustration, that it is decided that alternatives $X, Y$, and $Z$ are to be evaluated to improve the cob gasification system. To accomplish such an evaluation, Figure 1 can be converted to a diagraph such as Figure 2, and collapsed onto a sequential axis as in Figure 3. The sequence of Figure 3 becomes the system clock. The system sequence acquires system meaning when we know about the flow levels at different points in the sequence. How many trucks need to arrive at the field and when, for example, depends on the yield of the corn and the technology of the 

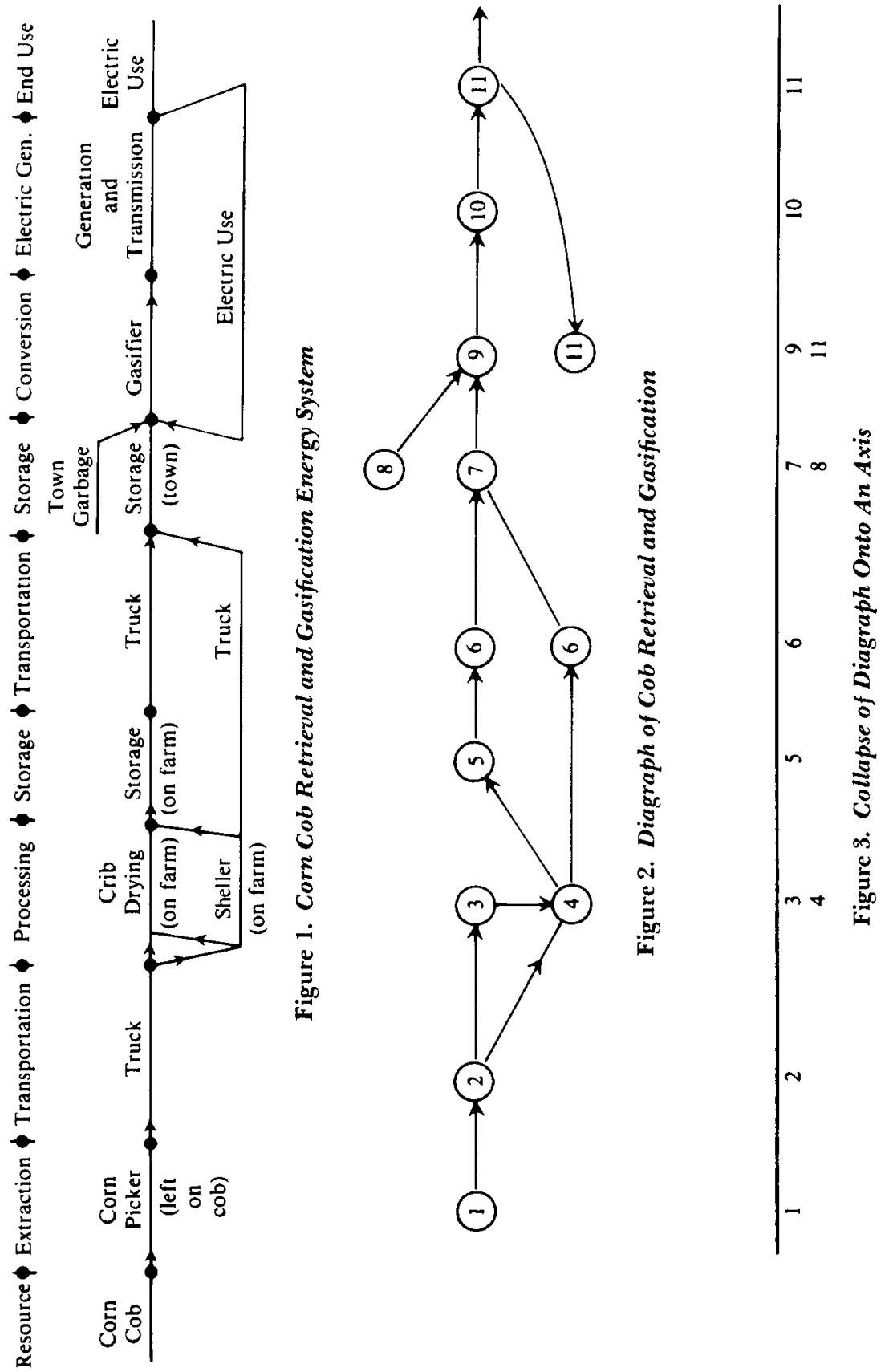

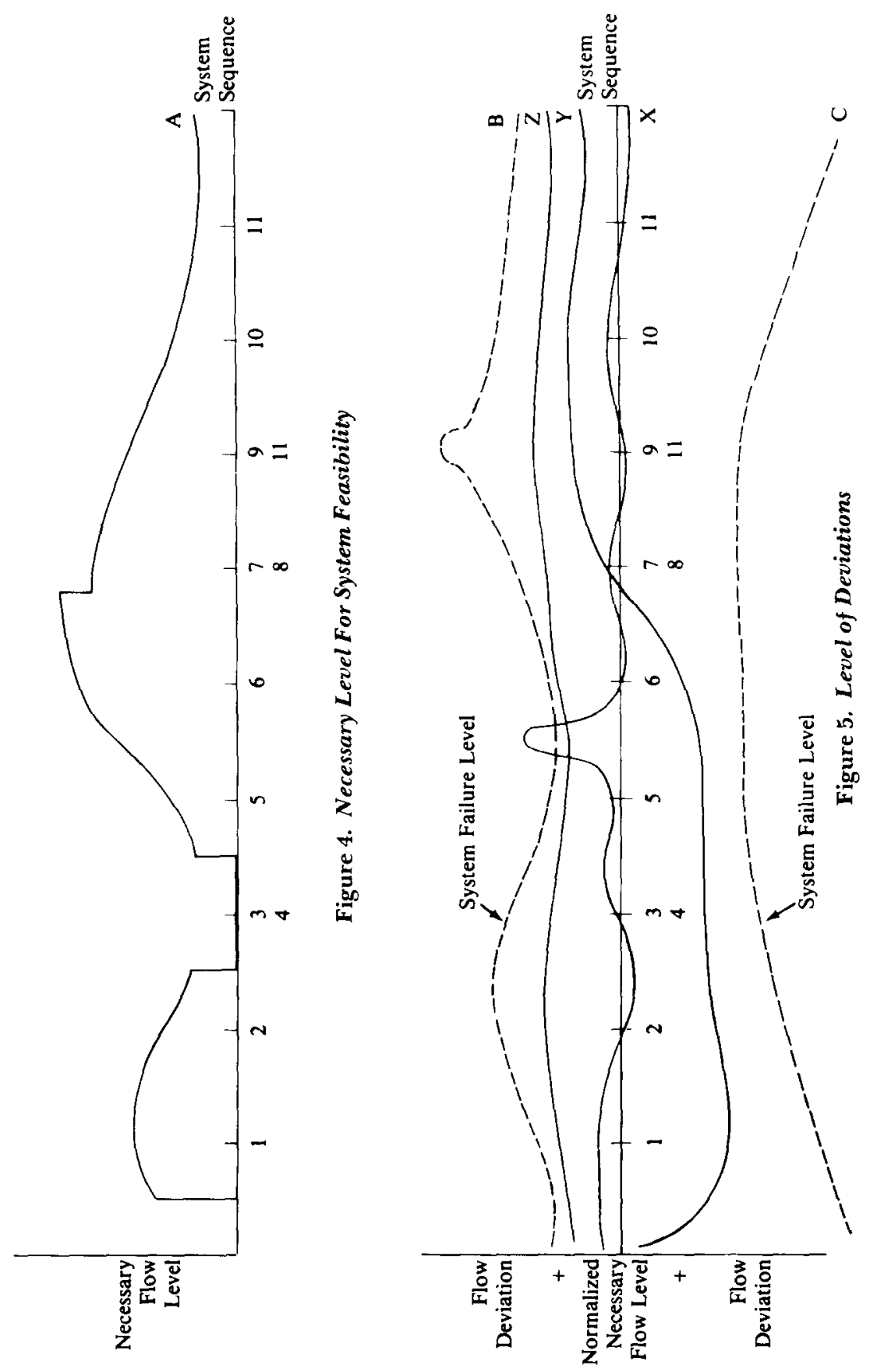
corn picker. Once the requisite, sufficient, or allowable levels are determined, evaluation can begin. There can be, for example, requisite levels of income and allowable levels of pollution. A composite of all three levels is designated as the necessary level in Figures 4 and 5.

As indicated in Figure 4, the necessary level may vary over the system sequence. Since it indicates the level needed to make the system feasible, it can be collapsed and normalized along the system sequence axis depicted in Figure 3. The flow at node 6 in Figure 5 would be at a much greater level than at node 2 , but both are equal from the view of system requirements; therefore they both fall on the horizontal axis in Figure 5.

The axes both above and below the feasibility level are positive in order to determine how much a scenario trajectory deviates from the feasibility level. Zero points in numbering are, of course, arbitrary and it is equally arbitrary to assume that deviations are positive in one direction and negative in the other. Deviations from a norm can be damaging to a system irrespective of their direction. In all social systems of prescribed behavior, there is a spectrum of permissible deviation from the norm. Two important deviations to consider in evaluating alternatives are critical level and delivery specificity. The critical level is the extreme extent of deviation allowable. For example, if more garbage and cobs are delivered than can be gasified, then health and rodent problems develop. If, on the other hand, too little is delivered, the system must shut down and electrical generation is no longer feasible. Delivery specificity designates how specifically delivery must fit the recipient node. The more finely tuned the technological system and the level of mechanization, the less tolerance for variance. Lines $B$ and $C$ in Figure 5 represent a composite of both critical tolerance and delivery specificity.

To evaluate alternatives $X, Y$ and $Z$ represented in Figure 5, we want to select the one with the least deviation from the norm. This can be determined by the sum of the differences between the trajectory and the system sequence axis, except in those cases where the trajectory penetrates the critical level represented by $B$ and $C$. This would eliminate alternative $X$, even though it would have the lowest sum of differences. Obviously alternative $Y$ would be selected. The idea is to fit a selected norm represented by the horizontal axis rather than maximize a function from an axis.

Alternative $Y$ was selected on the basis of a real time trajectory of one impact. Any real world problem, in contrast, would have multidimensional impacts for each alternative. The character of the problem 
will define the kind of indicator used to measure social impacts. With a real time approach to temporal evaluation, social indicators, instead of pecuniary prices, can be used as the measurement unit to compare alternative programs.

The real time concept applied to project evaluation is a step forward in time analysis. However, additional steps are needed to reach the level of social planning and system coordination necessary in the modern technological society.

\section{From Event Synchronization to Social Process Sequencing}

With the aid of the general summary contained in Figure 6, we can discuss the evolution of our time concepts, both in terms of the past and in terms of a needed future. It can be summarized as an evolution from event synchronization to social process sequencing. The evolution of technology is indicated across the top of Figure 6, the instruments or measures of time are along the left side, and the temporal concepts are arrayed outward from the intersection of the two axes. Figure 6 serves as a general summary of the relationship between technological
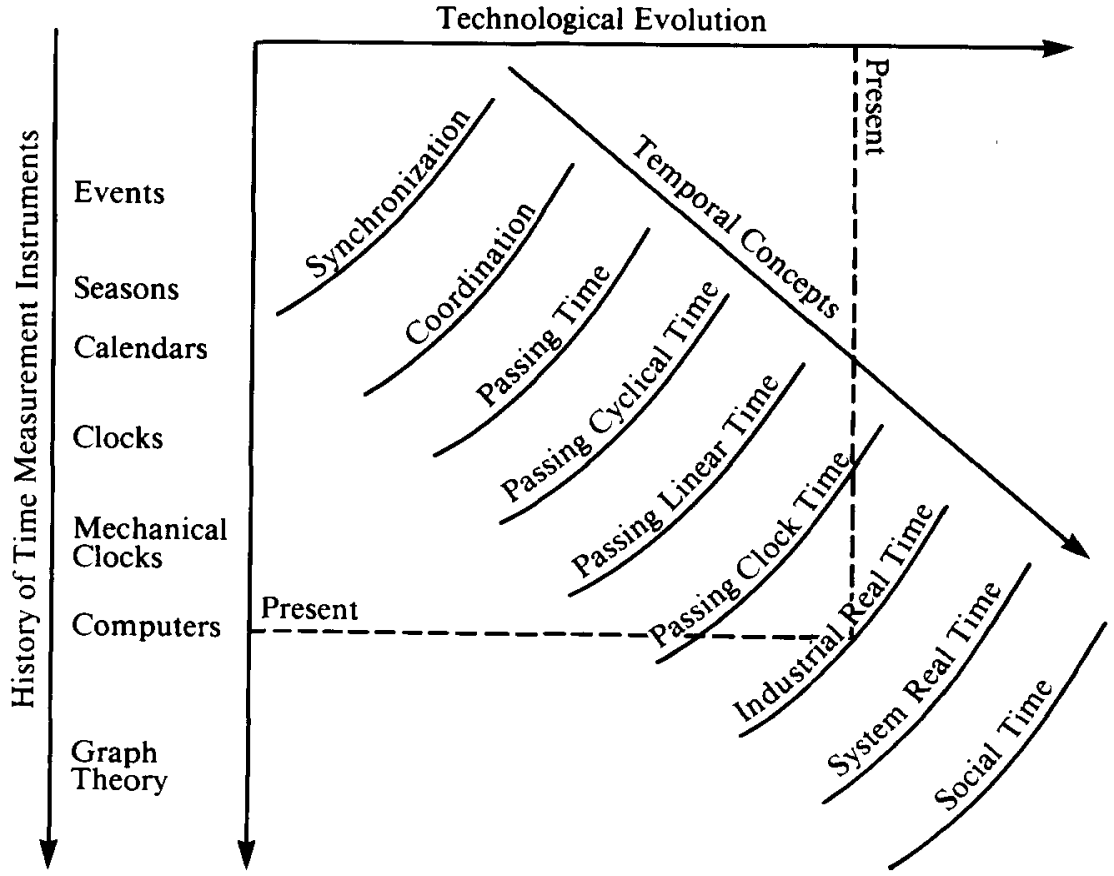

Figure 6. Evolution of Technology, Time Measurement Instruments, and Temporal Concepts 
evolution and temporal constructs; as technology changes, both the instruments for measuring time and temporal concepts change. The ordering of time concepts in Figure 6 does not mean to imply all the earlier concepts fade away upon the adoption of the more recent.

As stated above, in the simplest technological societies, only a few events had to be synchronized in order to facilitate social life. Time existed only when those events had to be synchronized or when historical occurrences had to be recorded. It did not exist the remainder of the day, week, or year. There were no clocks or a sense of time sequencing. Neither was time divided into units such as weeks or hours. There was no need for such measurements. Sandor Szalai points out that even today "in quite a number of poor African and Asian countries the overwhelming majority of the rural population has no access whatsoever to clocks, public or private, and cannot read time." 49 According to MaxNeef, the same is true in Latin America. He states, "the bond of the peasant with time is different, and has different meanings and consequences, from that of the urban individual, especially one who lives in a metropolitan business industrial environment. There is no doubt that the famous (and very destructive) slogan 'time is money' has no meaning whatsoever for a peasant."so

With the evolution of nomadic and agricultural societies, sociotechnical processes became more complex, thus more synchronization and coordination were needed. Planting, harvesting, and warfare require more refined coordination. In addition, because the seasons became more important to when and where the tribe moved or when crops were planted, the seasons replaced events as the main time instrument. This added a natural rhythm and a sense of passing to time as seasons changed with some regularity. The regularity was noted and divided in smaller units. Seasons were turned into calendars and hour dials were developed as the various heights of the sun were recorded. Even at this, time was not a continuum. According to Szalai "Nobody ever cared in Athens or Rome to divide the night into hours. What for? With the exception of a few guardsmen and revellers, the use of time stopped when darkness set in." $"$ 1

The regular rhythm of an organized society gave the sense of events passing along a time continuum. However the rate of technological change was so slow that life seemed to be repeating itself from year to year and from generation to generation. Therefore, the time construct was thought to be circular. As new technological combinations began to appear more rapidly, it became obvious that society was changing. Therefore, the time continuum ceased to be circular and began to move 
forward, finally becoming linear. The linear continuum became evenly divided into hours and minutes of uniform passing time. "The need for taking account of minutes, not to speak of seconds, arose only when people had already got accustomed to living 'by the clock' and to adapt their daily life, even 'minute' details of it, to the tick-tock of this mechanical device." 52 With the triumph of linear time,

present time was "compressed" until it was merely a point sliding continuously along the line which runs from past to future.... Present time became fleeting, irreversible and elusive. Man for the first time discovered that time, whose passing he had noted only in relation to events, did not cease even in the absence of events. As a result, an effort had to be made to save time, to use it rationally and to fill it with actions useful for man. The bells from the belfry, ringing out at regular intervals, were a constant reminder of the brevity of life, and a call to great actions which could give time a positive content. ${ }^{53}$

In the industrial era the clock is not just a measure or symbol of passing time. In the minds of that era it is passing time, both operationally and as conscious proof of the passing of time. The clock's 24-hour-perday, 60-minutes-per-hour and 60-seconds-per-minute has given the impression of an evenly divided flowing time to those living in an industrial society. Clock time, in conjunction with industrial society, has "established a clock work of its own that imposes its beat even more powerfully on everyday activities than the natural rhythm of the alternating nights and days and of the changing seasons had imposed itself on life in traditional agricultural civilization." 54 The commitment to and dependence upon the clock by industrial society should not be a surprise because the clock is a machine itself and, according to Clarence Ayres, "the clock has been called the master pattern of all subsequent expedients in the field of power driven machinery." 55

Technological advancement allowed for the development of science as well as industry. Since science was emphasizing the relativity of time, the scientific findings were inconsistent with the belief in absolute clock time. We might believe these findings would have made people more conscious of taking control of their own temporal arrangements. However, that has not been the case. "Social life in the industrially developed parts of the world, and especially in modern industrial surroundings, shows an ever-growing dependence on the clock and an ever-growing independence of the calendar." 56

Although social life continues with clock time, industrial processes are now being changed to real time. This has come about because of 
the continued expansion of science and technology. It is the result of the integration of holistic science, instrumentalist philosophy, computer science, and computerized industrial production processes. "Contemporary science was criticized as being narrowly compartmentalized around Aristotelian subdivisions of subject matter. The case was developed for science oriented around real-world events and concerned with the regulation and control of events in real time." 57 As stated earlier, the system determines the measurement instrument. It is not dependent upon the clock of passing time. Real time is defined in a system context that takes account of the appearance, duration, passage, and succession of events as they are interrelated within a system. Real time concerns temporary and situationally contingent events amenable to regulation and control. In addition "it results in an extension of human mastery over such events." 58 As real time is extended in industrial and computerized systems, its concept will begin to affect more and more spheres of social and personal life. As the author recommended above, the next step should be to extend the use of real time for project evaluation. With the spread of real time, the computer will replace the clock.

Technological evolution, along with holistic science, will continue to change temporal constructs and extend real time in use and in concept. The extension will be used for socio-technical-environmental spacetime planning and coordination. "Relative space is inseparably fused to relative time, the two forming what is called the spare-time manifold, or simply process. "s9 More and more, it is understood that local, regional, national, and supranational processes must be coordinated and controlled if humans are to solve problems. This will lead to system real time and beyond that to social time, where the events are not just sequenced by the system but the socio-technical-environmental system is determined by the conscious temporal concept of timeliness through discretionary social institutions.

The Lapps are currently suffering an income loss because of radiation contamination of their reindeer grazing area by the Chernobyl nuclear plant incident in Russia. The Mexicans have been suffering a loss of water because of the United States Colorado River dam system, which loses more water through evaporation than it preserves. These are supranational events that could have been foreseen and avoided with the application of scientific inquiry and the development of institutions such as international inspections of nuclear plants and water projects. The inquiry necessary for completing such scenarios was not completed because of the pell-mell rush for development and growth to fulfill the 
incessant command of passing time. That can change. Time can be tamed, inquiry enhanced, and institutions created. Human mastery over events can be and will be expanded, given the requirements of recent technology.

Space, time, location, and movement cannot be separated. Therefore, these concepts cannot be separated in our planning. "Without movement, whether tangible or intangible, there are no spatial relations, the main object of study in much of geography. Mere co-existence in space without any effect of one body or process on another is like time without change, or rather like change not producing other changes. ... Space (and time) seem to be discovered by movement, especially by locomotion."60

When we are talking about events and movement with regard to time and space we are, as the institutionalists have emphasized, talking about holistic processes. When it is understood that social processes are policy-based, then it is understood that process planning is necessary. For example there is a multinational interest, confirmed by treaties and other agreements, in the ducks, geese, and cranes that travel the flyways and staging areas of the United States. Yet the staging areas-wetlands, potholes, rivers, marshes-are constantly being destroyed, thereby leading to high rates of death and disease among the birds. If we want the birds, then their migration patterns must be coordinated with the environment and with human activity patterns. Events such as drawing irrigation water from the river, providing an adequate water flow in the riparian wetlands, and the arrival of the birds must be sequenced in time, space, and location, or the birds will not survive.

The kind of planning necessary for our interdependent technological system requires a different level than the simple one that just tried to fill the passing time of the clock with production events. We must now adjust and coordinate our beliefs, environment, technology, and so forth. It seems this is a step beyond real time where the system is used as the clock. This could be called social time where the system itself is structured.

Traditional time concepts and clocks are not sufficient for the spacetime coordination that will take place in the future. "It is not unreasonable to argue that the very fact that we conceptualize human activity as forming a stream flowing through time (and space) suggests that a classification into activity types, sets or modules is either not possible or that it produces a severe and unacceptable abstraction of reality." 61 In order to successfully plan, coordinate, and monitor we must change 
the mode of conceptual notion and abstraction. The "clocks" of the future are more likely to be akin to computerized matrices, graphs, and diagraphs. The basic reason graph theory is suggested as the likely format of our time instrument is that graph theory does not conceptualize society as flowing along in a stream, and it treats events as discernable entities. In addition, graph theory

is a general modeling system for relations. ... The use of the graph underlying a situation enables us to strip off initially unessential details. Even when some information is lost in looking only at the graph, this method of modeling may bring new insights by directing one's attention to the structural aspects of the relations being studied. Where theory exists about the nature of structural relations a graph or diagraph theoretic approach provides a means for testing theory. Where no theory exists or in the more likely situation of ill-defined theories in the social sciences, graphs and diagraphs may generate well-defined schemes. Sometimes it is useful to concentrate on part only of the relation being studied; instead of the whole graph, one looks at a sub-graph formed by deleting some vertices and/or edges from the original. ${ }^{62}$

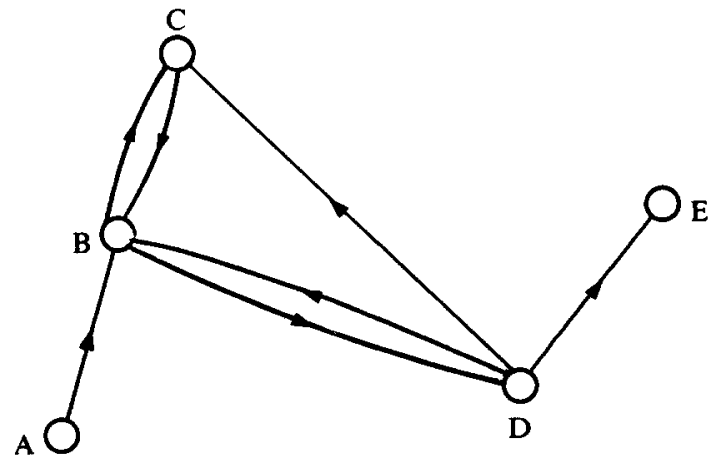

Figure 7. Sample Diagraph

A diagraph like Figure 7 can be used to represent the sequence of relations and the direction of deliveries among the components of the social system. Such articulation can be used to plan communication 
networks, or transportation systems, or pollution controls, or whatever needs to be coordinated in a timely manner.

The author has provided articles elsewhere on the use of matrices and diagraph theory for expressing institutional theory, defining socioeconomic processes, and conducting geobased planning in conjunction with remote sensing and computer mapping. ${ }^{63}$ The social fabric diagraph is consistent with activity sequencing called for by social time. Activity sequence

puts social events into a system which is ideally timed by the succession of events relevant to that system, that is by social time. In other words, reference to universal or clock time becomes secondary to the internalized timing which is defined by the nature of activity sequence structure. We have yet to develop a timing system which is internalized to the relationship between events in a socially relevant cycle. Clock time still dominates. ${ }^{64}$

Sequence methodologies will help us determine and sequence the elements in our institutional structure and process. As W.E. Moore explained:

Much of social behavior depends for its orderly qualities on common definitions, assumptions, and actions with regard to the location of events in time. Certain activities, for example, require simultaneous actions by a number of persons, or at least their presence at a particular time. ... Thus one element of temporal ordering is synchronization. Other activities require that actions follow one another in a prescribed order; thus sequence is a part of temporal order ... frequency of events during a period of time is critical; thus rate is also one of the ways that time impinges on social behavior. For all of these elements of social coordination the term timing is useful ... timing is an intrinsic quality of personal and collective behavior. If activities have no temporal order, they have no order at all. ${ }^{65}$

To order our social systems, we must leave behind passing time, and ultimately move beyond real time to social time. In this way we can achieve the planning necessary for a supranational technological society.

\section{Notes}

1. John R. Commons, Legal Foundations of Capitalism, Madison: University of Wisconsin Press, 1968 [1923]), p. 379.

2. Thomas J. Cottle and Stephen L. Kleinberg, The Present of Things Future: 
Explorations of Time in Human Experience (New York: The Free Press, 1974), p. 166.

3. Richard M. Gale, "Human Time," in The Philosophy of Time, ed. Richard M. Gale (Garden City, N.Y.: Anchor Books, 1967), p. 30.

4. Cottle and Kleinberg, The Present of Things Future, p. 166.

5. Ibid., p. 167.

6. Ibid., p. 168.

7. J.B. Priestly, Man and Time (Garden City, N.Y.: Doubleday \& Company, 1963), p. 160.

8. Ibid., p. 172.

9. John Adams and Uwe J. Woltemade, "Village Economy in Traditional India: A Simplified Model," Human Change 39 (Spring 1970): 49-56.

10. Cottle and Kleinberg, The Present of Things Future, p. 162.

11. Priestly, Man and Time, p. 152.

12. Ibid., p. 158.

13. Ibid.

14. J.L. Russell, "Time in Christian Thought," in The Voices of Time, ed. J.T. Fraser (London: Allen Lane, The Penguin Press, 1968), p. 66.

15. Germano Pattaro, "The Christian Conception of Time," in Cultures and Time (Paris: The UNESCO Press, 1976), p. 189.

16. Russell, "Time in Christian Thought," p. 66.

17. Geddes MacGregor, The Hemlock and the Cross: Humanism, Socrates, and Christ (Philadelphia: J. B. Lippincott, 1963), p. 91.

18. George C. Lodge, The New American Ideology (New York: Alfred A. Knopf, 1976), p. 58.

19. Priestly, Man and Time, p. 166.

20. Ibid., p. 64.

21. Kenyon B. DeGreene,Sociotechnical Systems: Factors in Analysis, Design, and Management (Englewood Cliffs, N.J.: Prentice-Hall, 1973), p. 207.

22. Manfred A. Max-Neef, From the Outside Looking in: Experiences in 'Barefoot Economics'(Uppsala: Dag Hammarskjold Foundation, 1982), p. 150.

23. Ibid., p. 140.

24. Ibid., p. 150 .

25. Priestly, Man and Time, p. 69.

26. Nicholas Georgescu-Roegen, Analytical Economics: Issues and Problems (Cambridge: Harvard University Press, 1966), p. 69.

27. Albert Einstein and Leopold Infeld, The Evolution of Physics, (Forge Village, Mass.: Simon \& Schuster, 1938), p. 6.

28. Robert E. Ornstein, The Psychology of Consciousness (New York: Harcourt Brace Jovanovich, 1977), p. 105.

29. Priestly, Man and Time, p. 67.

30. Ibid., p. 69.

31. Keith Floyd, "Of Time and the Mind," Fields, 10 (Winter 1973-74): 47-57.

32. Ibid., p. 50.

33. F. Stuart Chapin, Jr., Human Activity Patterns in the City: Things People Do in Times and Space (London: John Wiley \& Sons, 1974), p. 9.

34. Ibid., p. 10.

35. Ibid.

36. See Walter C. Neale's article, "Institutions," pp. of this issue. 
37. F. Gregory Hayden with Larry D. Swanson, "Planning through the Socialization of Property Rights: The Community Reinvestment Act," Journal of Economic Issues 14 (June 1980): 351-69, at p. 354.

38. Howard H. Pattee, "The Role of Instabilities in the Evolution of Control Hierarchies," Power and Control, ed. Tom Burns and Walter Buckley (Beverly Hills: Sage Publications, 1976), p. 172.

39. DeGreene, Sociotechnical Systems, p. 61.

40. Ibid.

41. Harry W. Pearson did not define an excess of unwanted entities as surpluses; however the concept of surplus used here is intended to be consistent with his concept of relative surplus. See Harry W. Pearson, "The Economy Has No Surplus: Critique of a Theory of Development" in Trade and Markets in Early Empires, ed. Karl Polanyi, et al., (Glencoe: The Free Press, 1957), pp. 320-341.

42. Real time is something of a misnomer; a term more descriptive of the concept is system time.

43. Edward A. Nelson, "A Working Definition of Real-Time Control," P-3089 (Santa Monica: The Rand Corporation, 1965), p. 18.

44. Harold Sackman, Computers, System Science and Evolving Society: The Challenge of Man-Machine Digital Systems (New York: John Wiley \& Sons, 1967) pp. 223-35.

45. Harold Sackman, "Futurists on the Future," Los Angeles Business \& Economics 6 (Summer 1981): 21-36.

46. Sackman, Computers, System Science and Evolving Society, p. 42.

47. Ibid., p. 43.

48. Matrix of Environmental Residuals for Energy Systems is explained in: Council on Environmental Quality, MERES and the Evaluation of Energy Alternatives, publication 041-011-0026-2 (Washington, D.C.: U.S. Government Printing Office, 1975).

49. Sandor Szali, "Time and Environment: The Human Use of Time," The New Hungarian Quarterly 19 (Summer 1978): 138-39.

50. Max-Neef, From the Outside Looking in, p. 139.

51. Szali, "Time and Environment," p. 134.

52. Ibid.

53. A.J. Gurevich, "Time as A Problem of Cultural History," Cultures and Time (Paris: UNESCO, 1976), p. 242.

54. Szali, "Time and Environment," p. 135.

55. Clarence E. Ayres, The Theory of Economic Progress, (New York: Schocken Books, 1962 [1944]), p. 144.

56. Szali "Time and Environment," p. 133.

57. Sackman, "Futurist on the Future," p. 250.

58. Ibid.

59. J.M. Blaunt, "Space and Process," Professional Geography 13 (1961): 1-7, quoted in Edward L. Ullman, "Space and/or Time Opportunities for Substitution and Prediction," Transactions Institute of British Geographers, New Series 4 (1979): 121-37.

60. Ullman, "Space and/or Time Opportunities for Substitution and Prediction," p. 127.

61. Don Parkes and W.D. Wallis, "Graph Theory and the Study of Activity 
Structure," in Human Activity and Time Geography, ed. Tommy Carlestein, Don Harkes, and Nigel Thrift (New York: John Wiley \& Sons, 1980), p. 78 .

62. Ibid., p. 81 .

63. F. Gregory Hayden, "Social Fabric Matrix: From Perspective to Analytical Tool," Journal of Economic Issues 16 (September 1982): 637-62; F. Gregory Hayden, "Organizing Policy Research Through the Social Fabric Matrix: A Boolean Digraph Approach," Journal of Economic Issues 16 (December 1982): 1013-26; and F. Gregory Hayden, "Integration of Social Indicators Into Holistic Geobased Models," Journal of Economic Issues 17 (June 1983): 325-34.

64. Parkes and Wallis, "Graph Theory and the Study of Activity Structure," p. 77.

65. Ibid., p. 76. 